\title{
Acute respiratory distress syndrome: we can't miss regional lung perfusion!
}

Paolo Pelosi ${ }^{1 *}$ and Marcelo Gama de Abreu $^{2}$

\begin{abstract}
In adult respiratory distress syndrome (ARDS), life-threatening hypoxemia may occur, dictating the need for differentiated ventilator strategies. Pronounced consolidation and/or atelectasis have been well documented in ARDS, but the contribution of regional perfusion to oxygenation has been poorly addressed. Evidence has accumulated that, in ARDS, regional perfusion is extremely variable and may affect oxygenation, independently from the amount of atelectatic-consolidated lung regions. Thus, the response in oxygenation to different ventilatory settings, both during controlled and assisted mechanical ventilation, should be interpreted with caution. In fact, gas exchange may be not determined solely by changes in aeration, but also redistribution of perfusion. Furthermore, regional perfusion can play an important role in worsening of lung injury due to increased transmural pressures. In addition, distribution of perfusion in lungs might affect the delivery of drugs through the pulmonary circulation, including antibiotics. In recent years, several techniques have been developed to determine pulmonary blood flow with increasing level of spatial resolution, allowing a better understanding of normal physiology and various pathophysiological conditions, but most of them are restricted to experimental or clinical research. Lung ultrasound and novel algorithms for electrical impedance tomography represent new promising techniques that could enable physicians to assess the distribution of pulmonary blood flow at the bedside. In ARDS, we cannot afford missing regional lung perfusion!

Please see related article: http://dx.doi.org/10.1186/s12871-015-0013-0.
\end{abstract}

Keywords: Acute respiratory distress syndrome, Pulmonary blood flow, Ventilator induced lung injury, Gas exchange, Lung imaging

\section{Background}

The acute respiratory distress syndrome (ARDS) is an acute life-threatening condition, triggered by different clinical disorders, and characterized by severe hypoxemia refractory to increased inspired oxygen fraction, and high mortality [1]. Hypoxemia is closely related to the consolidation or collapse of lung regions, which increase the intrapulmonary shunt. Accordingly, most strategies aimed at improving oxygenation in ARDS target at the improvement of aeration and ventilation.

Different imaging techniques such as computed tomography [2], electrical impedance tomography [3] and lung ultrasonography [4] have been used to investigate the distribution of aeration and/or ventilation in ARDS. However,

\footnotetext{
* Correspondence: ppelosi@hotmail.com

'Department of Surgical Sciences and Integrated Diagnostics, IRCCS San Martino IST, University of Genoa, Genoa, Italy

Full list of author information is available at the end of the article
}

arterial oxygenation results from the coupling between alveolar ventilation and perfusion. Therefore, a favorable distribution of regional perfusion could prevent deterioration of oxygenation, even in presence of non-aerated lung tissue.

\section{Main text}

Richter et al. [5] investigated the distribution of regional pulmonary blood flow in a model of acute lung injury induced by hydrochloric acid in rats. They found that 2 hours after injury, the pulmonary blood flow shifted away from injured regions, explaining at least in part a progressive improvement in oxygenation. These data confirm the importance of regional pulmonary blood flow for the pathophysiology of ARDS, while providing valuable insight into the clinical management of patients suffering from this syndrome.

The role of pulmonary perfusion in ARDS is important for different reasons. First, perfusion potentially interacts 
with and modulates ventilator induced lung injury. Second, it is a major determinant of pulmonary gas-exchange. Third, it reflects pulmonary vascular resistance, heart-lung interactions, venous return to the heart, and even systemic hemodynamics [6]. Fourth, experimental studies showed that a higher transmural pressure, which results from the pressure gradient between the alveoli-interstitium and intracapillary pressure, promotes higher epithelium and endothelium injury, as well as lung edema $[7,8]$.

Different mechanisms can explain shifts in regional perfusion, including obstruction or compression of pulmonary capillaries due to swelling of endothelial cells, and pulmonary hypoxic vasoconstriction. In ARDS patients, redistribution of pulmonary blood flow contributes only slightly to maintenance of oxygenation [9], suggesting that hypoxic vasoconstriction is blunted, which differs from the data presented by Richter et al. [5]. Possible explanations for this discrepancy are differences in the etiology of ARDS, species, as well as type of ventilation, i.e. assisted vs. spontaneous.

During pressure support ventilation, improvements in oxygenation were associated with a redistribution of perfusion towards well-aerated, non-dependent lung regions, without evident alveolar recruitment $[10,11]$. In contrast, biphasic positive pressure ventilation with additional mandatory breaths $[12,13]$, as well as variable controlled ventilation [14], promoted redistribution of perfusion towards dependent lung regions, and alveolar recruitment. Differences in the pattern of redistribution of perfusion might be explained by: 1) regional pleural pressures during inspiration; 2) mean airway pressure. In fact, time cycling compared to flow cycling promotes higher mean airway pressure yielding better lung stabilization. The redistribution of regional pulmonary blood flow can explain at least in part possible beneficial effects of assisted ventilation on ventilator-induced lung injury [15-17].

Ideally, assessment of lung perfusion should be performed in real-time. Unfortunately, such methods are not available at bedside yet. For research, different techniques have been proposed, including single photon emission computed tomography, positron emission tomography [18], and multi-detector row computed tomography [19]. For clinical practice, a new electrical impedance tomographybased method that quantitatively estimates regional lung perfusion based on first-pass kinetics of a bolus of hypertonic saline contrast has been reported [20-22]. In addition, color Doppler ultrasound might also give information about regional perfusion in non-aerated lung regions $[23,24]$.

\section{Discussion}

The better understanding of the role of regional perfusion could have important implications for daily clinical practice. First, the response in oxygenation to different ventilatory settings should be interpreted always with caution, since they might be not determined by lung recruitment or derecruitment, but redistribution of perfusion. Second, an excessive pulmonary blood flow, either global or regional, can contribute to ventilator-induced lung injury; thus, optimal fluid balance and adequate monitoring should be mandatory. Third, low tidal volume should be used to prevent or minimize ventilator-induced lung injury, and positive end-expiratory pressure preferably titrated on respiratory mechanics changes than oxygenation. A more detailed and comprehensive approach, including bedside lung imaging, hemodynamics, gasexchange and mechanics should be preferred, at least in most severe cases. Fourth, due to the unpredictable distribution of blood flow, it is likely that drugs delivered to the lungs, like intravenous antibiotics, will not reach in adequate amount the affected regions, possibly compromising their effectiveness, specially in assisted ventilation. We believe that the evaluation of regional perfusion at the bedside should be implemented more often to follow the course of the disease and clinical treatment.

\section{Conclusions}

The experimental study by Richter et al. [5] provides further evidence that regional perfusion affects ventilatorinduced lung injury, and importantly modulates gasexchange in ARDS. In recent years, several techniques have been developed to determine pulmonary blood flow with increasing level of spatial resolution, allowing a better understanding of normal physiology and various pathophysiological conditions, but most of them are restricted to experimental or clinical research. Lung ultrasound and novel algorithms for electrical impedance tomography represent new promising techniques that could enable physicians to assess the distribution of pulmonary blood flow at the bedside. In ARDS, we cannot afford missing regional lung perfusion!

\section{Abbreviations}

ARDS: Acute respiratory distress syndrome.

\section{Competing interests}

The authors declare that they have no competing interests.

\section{Authors' contributions}

Both authors drafted and approved the manuscript.

\section{Authors' information}

Commentary article: Richter T, Bergmann R, Musch G, Pietzsch J, Koch T. Distribution of pulmonary blood flow 2 hours after acid aspiration measured by positron emission tomography. BMC Anesthesiology 2015, in press).

\section{Author details}

${ }^{1}$ Department of Surgical Sciences and Integrated Diagnostics, IRCCS San Martino IST, University of Genoa, Genoa, Italy. ${ }^{2}$ Department of Anesthesiology and Intensive Care Medicine, Pulmonary Engineering Group, University Hospital Carl Gustav Carus; Technische Universität Dresden, Dresden, Germany. 
Received: 19 February 2015 Accepted: 24 February 2015 Published online: 18 March 2015

\section{References}

1. Force ADT, Ranieri VM, Rubenfeld GD, Thompson BT, Ferguson ND, Caldwell E, et al. Acute respiratory distress syndrome: the Berlin Definition. JAMA. 2012;307:2526-33.

2. Cressoni M, Cadringher $P$, Chiurazzi C, Amini M, Gallazzi E, Marino A, et al. Lung inhomogeneity in patients with acute respiratory distress syndrome. Am J Respir Crit Care Med. 2014;189:149-58.

3. Lowhagen $\mathrm{K}$, Lundin S, Stenqvist O. Regional intratidal gas distribution in acute lung injury and acute respiratory distress syndrome-assessed by electric impedance tomography. Minerva Anestesiol. 2010;76:1024-35.

4. Bouhemad B, Mongodi S, Via G, Rouquette I. Ultrasound for "lung monitoring" of ventilated patients. Anesthesiology. 2015;122:437-47.

5. Richter T, Bergmann R, Musch G, Pietzsch J, Koch T: Distribution of pulmonary blood flow 2 hours after acid aspiration measured by positron emission tomography. BMC Anesthesiology 2015, in press

6. Luecke T, Meinhardt JP, Herrmann P, Weiss A, Quintel M, Pelosi P. Oleic acid vs saline solution lung lavage-induced acute lung injury. Chest. 2006;130:392-401.

7. Broccard AF, Hotchkiss JR, Kuwayama N, Olson DA, Jamal S, Wangesteen $\mathrm{DO}$, et al. Consequences of vascular flow on lung injury induced by mechanical ventilation. Am J Respir Crit Care Med. 1998;157:1935-42.

8. Hotchkiss JR, Blanch L, Murias G, Adams AB, Olson DA, Wangesteen DO, et al. Effects of decreased respiratory frequency on ventilator-induced lung injury. Am J Respir Crit Care Med. 2000;161:463-8.

9. Brimioulle S, Julien V, Gust R, Kozlowski JK, Naeije R, Schuster DP. Importance of hypoxic vasoconstriction in maintaining oxygenation during acute lung injury. Crit Care Med. 2002;30:874-80.

10. GamadeAbreu M, Spieth P, Pelosi P, Carvalho AR, Walter C, Schreiber-Ferst $A$, et al. Noisy pressure support ventilation: A pilot study on a new assisted ventilation mode in experimental lung injury. Crit Care Med. 2008;36:818-27.

11. Carvalho AR, Spieth PM, Guldner A, Cuevas M, Carvalho NC, Beda A, et al. Distribution of regional lung aeration and perfusion during conventional and noisy pressure support ventilation in experimental lung injury. J Appl Physiol. 2011;110:1083-92.

12. Neumann P, Wrigge H, Zinserling J, Hinz J, Maripuu E, Andersson LG, et al. Spontaneous breathing affects the spatial ventilation and perfusion distribution during mechanical ventilatory support. Crit Care Med. 2005:33:1090-5.

13. Guldner A, Braune A, Carvalho N, Beda A, Zeidler S, Wiedemann B, et al. Higher levels of spontaneous breathing induce lung recruitment and reduce global stress/strain in experimental lung injury. Anesthesiology. 2014;120:673-82.

14. Spieth PM, Carvalho AR, Pelosi P, Hoehn C, Meissner C, Kasper $K$, et al. Variable tidal volumes improve lung protective ventilation strategies in experimental lung injury. Am J Respir Crit Care Med. 2009;179:684-93.

15. Saddy F, Oliveira GP, Garcia CS, Nardelli L, Rzezinski AF, Ornellas D, et al. Assisted ventilation modes reduce the expression of lung inflammatory and fibrogenic mediators in a model of mild acute lung injury. Intensive Care Med. 2010;36:1417-26.

16. Spieth PM, Carvalho AR, Guldner A, Kasper M, Schubert R, Carvalho NC, et al. Pressure support improves oxygenation and lung protection compared to pressure-controlled ventilation and is further improved by random variation of pressure support. Crit Care Med. 2011;39:746-55.

17. Carvalho NC, Guldner A, Beda A, Rentzsch I, Uhlig C, Dittrich S, et al. Higher levels of spontaneous breathing reduce lung injury in experimental moderate acute respiratory distress syndrome. Crit Care Med. 2014;42:e712-25.

18. Bellani G, Amigoni M, Pesenti A. Positron emission tomography in ARDS: a new look at an old syndrome. Minerva Anestesiol. 2011;77:439-47.

19. Grieser C, Goldmann A, Steffen IG, Kastrup M, Fernandez CM, Engert U, et al. Computed tomography findings from patients with ARDS due to Influenza A (H1N1) virus-associated pneumonia. Eur J Radiol. 2012;81:389-94.

20. Reinius H, Jonsson L, Gustafsson S, Sundbom M, Duvernoy O, Pelosi P, et al. Prevention of atelectasis in morbidly obese patients during general anesthesia and paralysis: a computerized tomography study. Anesthesiology. 2009;111:979-87.

21. Borges JB, Suarez-Sipmann F, Bohm SH, Tusman G, Melo A, Maripuu E, et al. Regional lung perfusion estimated by electrical impedance tomography in a piglet model of lung collapse. J Appl Physiol. 2012;112:225-36.
22. Reinius H, Borges JB, Freden F, Jideus L, Camargo ED, Amato MB, Hedenstierna G, Larsson A, Lennmyr F: Real-time ventilation and perfusion distributions by electrical impedance tomography during one-lung ventilation with capnothorax. Acta Anaesthesiol Scand 2015, doi:10.1111/aas.12455. [Epub ahead of print].

23. Yuan A, Yang PC, Lee L, Wu HD, Kuo SH, Luh KT, et al. Reactive pulmonary artery vasoconstriction in pulmonary consolidation evaluated by color Doppler ultrasonography. Ultrasound Med Biol. 2000;26:49-56.

24. Corradi F, Brusasco C, Pelosi P. Chest ultrasound in acute respiratory distress syndrome. Curr Opin Crit Care. 2014;20:98-103.

\section{Submit your next manuscript to BioMed Central and take full advantage of:}

- Convenient online submission

- Thorough peer review

- No space constraints or color figure charges

- Immediate publication on acceptance

- Inclusion in PubMed, CAS, Scopus and Google Scholar

- Research which is freely available for redistribution

Submit your manuscript at www.biomedcentral.com/submit
C) Biomed Central 